\title{
İç Mimarlık Mesleğinin Gelecekteki Çalışma Alanları Üzerine Bir Araştırma: Servis Tasarımı
}

\author{
Çağla GÜMÜŞÇÜ ${ }^{1 *}$, Deniz DEMIRARSLAN²
}

Öz

Günümüzde tasarımın dinamikleri mekânlardan mobil uygulama arabirimlerine kadar hızla değişmektedir. Beğenileri analiz ederek daha kaliteli kullanıcı deneyimi sunan, kullanıcısı ile bağ kurabilen ve tüm detayları ile birlikte bütüncül bir yaklaşımla tasarlanmış mekânlar ilgi görmektedir. Fiziksel mekânlardaki tasarımın bütüncül olarak ele alınması, mekândaki mobilyadan donanımsal ürünlere kadar devam etmesi gerekmektedir. Gelişen teknoloji ile birlikte tasarım bir intiyaçtan doğarak, estetik ve fonksiyon anlamında çok daha fazlasını deneyimleme imkânı sunmaktadır. Bu noktada, servis tasarımı iç mimari tasarım bağlamında, mekânın temas noktalarının kullanıcının deneyimini geliştirmek amacıyla planlanması ve düzenlenmesi eylemi olarak tanımlanmaktadır. Bu kavram kapsamında, insanı tasarımlarının odak noktasına yerleştirmeyi amaçlayan yeni ofis yapılanmaları deneyim ofisleri adı altında gelişmektedir. Deneyim tasarımı ofisleri tasarım araştırmacıları, iç mimarlar, mimarlar, servis tasarımcıları ve iletişimcilerden oluşmaktadır. İç mimarlık mesleği bu sürecin içerisinde kendi yerini korumaya devam etmektedir. Ancak bu bağlamda gelişmekte olan ofis yapılanmalarının, benimsedikleri bütüncül tasarım anlayışı ile birlikte barındırdığı farklı uzmanlık alanlarının tek bir tasarımcı kimliği altında toplanması söz konusu olmaktadır. İnsan odaklı tasarımı benimseyen bu yaklaşım, tasarımın günümüzdeki ve yakın gelecekteki kapsamını tanımlamaktadır. Bu bağlamda, tasarımcı ve iç mimar kavramları tanımlandıktan sonra gelişmekte olan servis tasarımı kavramı iç mekân tasarımı kapsamında irdelenecektir. Çalışma, yeni ofis yapılanmalarının incelenmesi ve yorumlanması ile detaylandırılacaktır. Sonuç bölümünde ise araştırmanın amacı olan iç mimarlık mesleğinin gelecekteki kapsamı, çalışma bağlamında yapılan araştırmalar ışığında irdelenecektir.

Anahtar Kelimeler: İc Mimarıı, Tasarım, Deneyim Tasarımı Ofisleri, Servis Tasarımı, Fütürizm

\section{A Research on the Future Areas of Interior Architecture Profession: Service Design}

\begin{abstract}
\footnotetext{
${ }^{1}$ İç Mimar, Kocaeli Üniversitesi, SBE, İç Mimarlık Anasanat Dalı, cagla.gmsc@gmail.com

2 Doç.Dr., Kocaeli Üniversitesi, Mimarlık ve Tasarım Fakültesi, İç Mimarlık Bölümü

*ilgili yazar / Corresponding author: Çağla Gümüşçü cagla.gmsc@gmail.com
}

Nowadays, the dynamics of design change rapidly from places to mobile application interfaces. The places are attracted by a holistic approach that provides a better quality user experience by analyzing the likes, connecting with the user and with all the details. The design of physical spaces should be considered as holistic, from furniture in space to hardware products. With the developing technology, the design emerges from a need offers the opportunity to experience much more in terms of aesthetics and function. At this point, the service design is defined as the action of planning and 
arranging the contact points of the space in order to improve the user's experience in the context of interior design. Within the scope of this concept, new office structures aim to place people at the focal point of their designs and develop under the name of experience offices. Experience design offices consist of design researchers, interior designers, architects, service designers and communicators. Interior architecture profession continues to maintain its place in this process. However, in this context, it is possible to gather different fields of expertise, which together with the integrated design approach, develop under a single designer identity. This approach, which adopts human-centred design, defines the present and future scope of design. In this context, after defining the concepts of designer and interior architect, the concept of developing service design will be examined within the scope of interior design. The study will be elaborated by examining and interpreting new office structures. In the conclusion section, the future scope of the interior architecture profession, which is the aim of the research, will be examined in the light of the research done in the context of the study.

Keywords: Interior Architecture, Design, Experience Design Offices, Service Design, Futurism

\section{GiRiş}

İç mimarlık mesleğinin, çok yönlülüğü ve farklı disiplinleri bir arada bulundurması sebebiyle, birçok farklı meslek grubu tarafından icra edildiği görülmektedir. Esasen iç mimarlık, örgütlenmeyi oluşturan ögelerin estetik ve fonksiyonel değerler kapsamında mekânın ya da mekân elemanının bir iç mimar tarafından tasarlanmasını kapsamaktadır (Kaptan, 1998, s.64). İnsanın ve toplumun mekân ihtiyacı bir iç mimarlık yapıtının oluşmasını gerektiren nedendir. Mekân ihtiyacı eşya ve eylemler için hacim intiyacı, varlığımızı sürdürmek için güvenlik intiyacı, yaşamı sürdürmek için konfor ve estetik intiyacı olarak tanımlanır. İç mimarlık bu ihtiyaçları karşılayarak mekân oluşturan ve örgütleyen bir tasarım disiplinidir (Demirarslan\&Demirarslan, 2017, s.114).

Geçmişten günümüze iç mimarlık ve mekân tasarım anlayışı teknolojideki ilerlemeler ile birlikte farkı bir hal almaktadır. Geçmişte iç mimarlık disiplininde mekân tasarımının amacı, fonksiyona yönelik işlevsel bir mekân oluşturabilmek olarak tanımlanmaktadır. Özellikle son yıllarda dünyadaki teknolojik, bilimsel gelişmeler paralelinde iç mekân tasarımında kullanıcının mekân algısını geliştirmeye yönelik mimari araştırmalara ihtiyaç duyulmaya başlanmıştır. Günümüzde iç mekân tasarımı geçmiştekinden farklı olmak üzere mekânın fiziksel kurgusunun yanı sıra yaratacağı psikolojik algıyı da gözeterek insanlar için daha iyi bir mekân yaratma amacı taşımaktadır. Bu kavram kapsamında bakıldığında insan odaklı tasarım yaklaşımı günümüz iç mekân tasarım anlayışının odak noktasında yer almaktadır. İç mimarların yeni görevi tasarladıkları mekânı kullanıcı odaklı olarak biçimlendirmesi; onların fiziksel ve psikolojik ihtiyaçlarına en uygun şekilde cevap vermesi olarak tanımlanabilir.

$\mathrm{Bu}$ çalışmada, öncelikle tasarım, tasarımcı, iç mimar kavramlarının tanımları yapılacaktır. Bu bağlamda, günümüz iç mekân tasarımının geldiği nokta ve tasarımı uygulayan farklı uzmanlık alanlarında kendini geliştirmiş kişilerin, tasarım anlayışındaki gelişmeler ile birlikte tasarımcı kimliği altında şekillenmesi ve bu yaklaşımın uygulandığı ofis yapılanmalarının incelenmesi çalışmanın kapsamını oluşturmaktadır. Servis tasarımı kavramı, genel tanımı ve iç mimari ile ilişkisi olarak iki başlık altında ele alınarak, söz konusu ofis yapılanmaları üzerinden elde edilen bulguların, günümüz iç mimari tasarım anlayışı ve etkilerine yönelik boyutları üzerinde çalışılmıştır. Yukarıda belirtilen amaçlara ulaşmak için makale genelinde literatür taraması ışığında kavramsal çerçeve oluşturulmuş, analiz ve sentez yöntemleri kullanılarak sonuca varılmıştır. 
Araştırma kapsamında incelenen örnekler birçok farklı uzmanlık alanından tasarımcıların tek bir çatı altında birleştiği deneyim ofislerinin işlerinden seçilmiştir. Çalışmada iç mimarın rolü irdelenerek elde edilen insan-mekân etkileşimi ile algılama bulguları birlikte değerlendirilerek, iç mimar kavramının gelecekteki kapsamına yönelik veriler geliştirilmesine çalışılmıştır.

\section{TASARIM, TASARIMCI, IÇ MIMAR: GÜNÜMÜZDEKI TASARLAMA EYLEMI}

Tasarım kavramı temel bir insan eylemi olarak nitelendirilmektedir. Tasarımın bir eylemi niteleyerek nihai ürünle birlikte arada geçen süreci kastettiği söylenebilir (Ökten, 2012, s.4). Tasarım, Türkçe sözlükte "zihinde canlandırılan biçim" olarak açıklanmaktadır (TDK, 2019). En yalın haliyle, olması veya yapılması istenen bir şeyin zihinde canlandırılması tasarım eylemi ile birlikte biçimlendirilmektedir. Bu bilgiler ışığında tasarım, düşünme ve zihinde canlandırma odaklı, yaratıcı bir analiz sonucu oluşum süreci olarak tanımlanabilir.

Atakan'a (2014, s.1) göre; tasarım, yaratıcılık gerektiren bir problem çözme işlemidir. Zihinsel bir eylemi temel alan problem çözme, tasarım süreci bağlamında, yaratıcılıkla iç içe geçmiş, döngüsel bir süreç olarak kabul edilebilir. Bu döngüsel süreç kapsamında tasarım, birçok şekilde tanımlanabilen ve farklı sonuçları olan problemlerin, çözümlerini yaratma süreci olarak tanımlanmaktadır. Bu süreçte karşılaşılan problemler, her tasarımın kendi bağlamı içinde farklı bir düşünme ile belirlenen yöntem ve çözüm önerileri içermektedir. Bu bağlamda değerlendirildiğinde, süreç içinde eylemi gerçekleştiren, tasarımı yapan kişi tasarımcı olarak nitelendirilmektedir (Şekil 1). İç mimar ise bir mekânın veya yapının işlev ve estetik bakımından kurgusunu oluşturan, bu süreçte kullanıcının fiziksel ve ruhsal özelliklerini de göz önüne alarak mekânı örgütleyen, tasarlayan kişi olarak tanımlanabilir (TDK, 2019). İç mimar, insan ve çevre ekolojilerini sentezleyen ve bilimi tüm duygulara hitap edecek biçimde güzelliğe çeviren kültürel sermayeyi yorumlayan dönüştüren ve düzenleyen mekân yapıcısıdır (Hayles, 2015, s.100-108). Bir diğer tanıma göre iç mimar, iç mekân yapı bileşenlerini ve donatı elemanlarını detaylı olarak tasarlayarak mekânların ve yakın çevresinin kullanıcı intiyaçları ile ölçülerini dikkate alarak estetik açıdan uygun olmasını sağlar (Kazamia ve Kafaridou, 2010, s. 100-108). Meslek olarak 19. Yüzyılın ortalarında çıkmış olan iç mimarlık mesleği özellikle 20. Yüzyılın ikinci yarısından itibaren yeni tasarım eğilimleri ile gelişim göstermiştir.

Endüstrileşme ve son yıllardaki teknolojik gelişmeler toplumun yaşam şeklini ve intiyaçlarını değiştirerek yeni kullanıcı gereksinimleri ortaya çıkarmaktadır. Bu kapsamda ortaya çıkan yeni gereksinimler yeni tasarım ürünleri gerektirmekte, yeni ürün ise yeni ihtiyaçlar için daha önce hiç denenmemiş olan bir tasarım uygulaması yapılmasına yol açmaktadır. Geçmişte tasarlanan mekânların tek bir işleve sahip olduğu görülmektedir. Günümüzde tasarlanan mekânlar birden fazla işlevi kapsamaktadır. Örneğin, ders çalışma eylemi kahve içilen bir mekânda gerçekleştirilebilmektedir. Çalışma alanları, dinlenme alanları ve diğer çalışanlar ile etkileşim kurma olanağı sağlayan mekânlar içermektedir. Günümüzde çağdaş tasarlama eylemi, çok fonksiyonlu bu mekânların meydana çıkması ile birlikte gelişen bir tasarım bileşkesi olarak devam etmektedir. Toplumun gereksinimlerindeki değişimler bugünkü tasarlama eyleminin oluşmasındaki en önemli etkenlerdir. Bütüncül ve sistemli yaklaşımların toplumun intiyaç ve gereksinimlerine daha kaliteli karşılık verdiği görülmektedir. Bu noktada, tüm bu gereksinimlere cevap verebilecek yeni mekânların ve alanların tasarlanması zorunluluk haline gelmektedir. Teknolojideki ilerlemelerin malzeme ve yapım teknikleri bağlamında sağladığı olanaklar, toplumun 
gereksinimleri için alternatiflerini arttırmakta ve dolayısıyla tasarlama eylemi de bu ölçüde gelişmektedir.

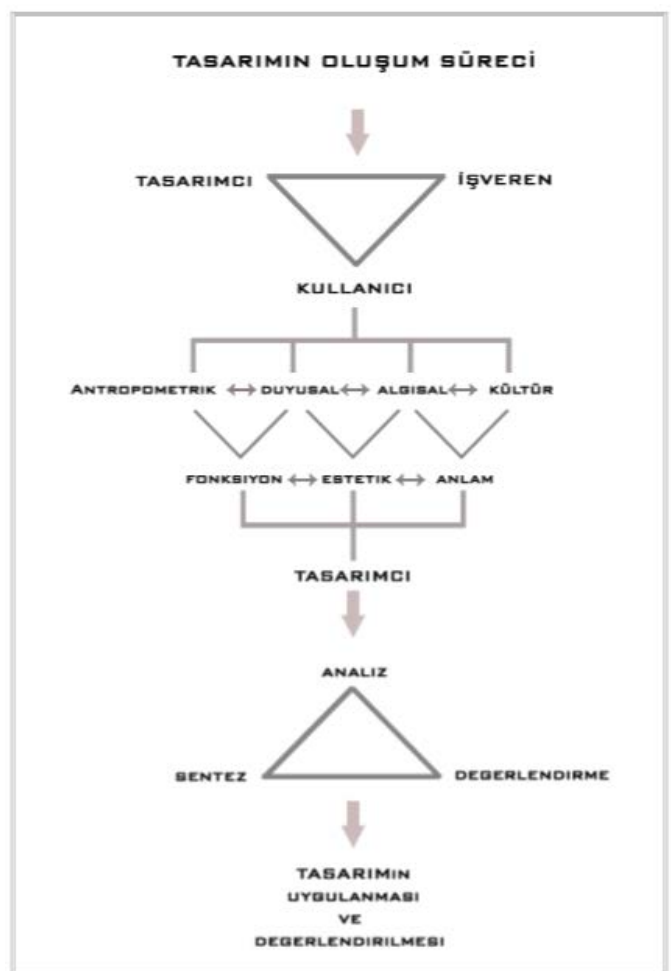

Şekil 1. Tasarımın Oluşum Süreci (Özkan, 2007, s.161)

Değişen intiyaçların büyüklüğü ve karmaşıklığı karşısında, tasarlama eylemini gerçekleştiren tasarımcıyı yönlendirmek adına birçok yeni teknik ve metot araştırmaları yapılmaktadır. Bu bağlamda, tasarım sürecinin başlı başına bir iletişim süreci olduğu görülmektedir. Bu süreçte gelişen yeni kavramlardan biri, teknolojinin gelişmesiyle birlikte 1980'li yıllarda hayatımıza girmiş olan servis tasarımı kavramıdır. Tasarlayıcı olarak iç mimarın rolü bu kavramın gelişmesi ile birlikte farklı bir boyuta geçmektedir.

\section{BÜTÜNCÜL TASARIM YAKLAŞIMI VE SERVIS TASARIMI KAVRAMI}

Günümüzde tasarımın dinamikleri mekânlardan mobil uygulama arabirimlerine kadar hızla değişmektedir. Beğenileri iyi analiz ederek daha kaliteli kullanıcı deneyimi sunan, kullanıcısı ile bağ kurabilen ve tüm detayları ile birlikte bütüncül bir yaklaşımla tasarlanmış mekânlar ilgi görmektedir. Fiziksel mekânlardaki tasarımın kapsamlı olarak ele alınması, mekândaki mobilyadan donanımsal ürünlere kadar devam etmesi gerekmektedir. Bu noktada, tasarlanacak ürün veya mekâna yaklaşım biçimi önem kazanmaktadır. Söz konusu bağlamda mekân tasarımı, bütüncül tasarım yaklaşımı kavramı ile ele alınmaktadır.

Bütüncül yaklaşımın temelinde, bütüncül düşünce anlamına gelen holistik düşünce yatmaktadır. Holistik düşünce Arıtan'ın "Evrendeki her şeyin aynı bütünün parçaları olduklarını, birbirlerinden haberdar olarak tek bir sistem şeklinde hareket ettiklerini ve birbirleriyle ilişki, iletişim ve etkileşim içinde bulunduklarını ortaya koymaktadır. Var olan her birim, diğerlerini etkileme, değiştirme ve yönlendirme özelliklerine sahip olmaktadır. Bu nedenle de, en küçük bir birim bile gereklidir, önemlidir ve değerlidir." cümleleri ile tanımlanmaktadır (URL-1). Bu bilgi ışığında tasarım bağlamında, mekânı bir bütün 
olarak ele almak ve parçalar arası ilişkiyi doğru kurarak o ilişkiyi en verimli şekilde yansıtabilmek, bütüncül tasarım yaklaşımının temelini oluşturmaktadır.

Esasen bütüncül tasarım anlayışı yeni bir kavram değildir. Tümel sanat yapıtı anlamında Almanca bir sözcük olan 'Gesamkunstwerk' Türkçe adıyla 'Bütüncül Tasarım' aynı üslup ve sanatsal anlatımla gerçekleştirilmiş resim, heykel, bezeme, mobilya ve diğer uygulamalı sanat ürünlerinin bir mimarlık ürününün bünyesinde birleştirilip bir araya gelişi olarak tanımlanmaktadır ve 20. Yüzyılın ilk yarısında sanat ve tasarım alanında yaygın bir şekilde kullanılmıştır (Demirarslan, 2018, s.34; Vidalis, 2010). Bu dönemde özellikle mimarlar tasarlamış oldukları binanın iç mekânlarını, mobilyalarını, tüm aksesuarlarını ve sanat ögelerini birlikte tasarlamışlardır.

Ancak bütüncül tasarım günümüzde gelişen teknoloji ile birlikte bir tasarım ihtiyacından doğarak, kullanıcısına işlev, estetik ve sonuç anlamında çok daha fazlasını deneyimleme imkânı sunmaktadır. Bu noktada bir diğer kavram olan servis tasarımı, iç mimari tasarım sürecinin etkili olması için en etkili yol olarak karşımıza çıkmaktadır. Servis tasarımı, kullanıcının ve çalışanın deneyimini doğrudan iyileştirmek ve dolaylı olarak kullanıcı deneyimini geliştirmek için bir işletmenin kaynaklarını kişi, mekân ve süreçleri planlama ve organize etme aktivitesi olarak tanımlanmaktadır (URL-2). Bu bağlamda, servis tasarımı kavramı iç mimarlık odağında, mekânın ve donatılarının, kullanıcının deneyimini geliştirmek amacıyla bütüncül bir tasarım anlayışı ile planlanması ve düzenlenmesi eylemini geliştirmek olarak nitelendirilebilmektedir (Şekil2).

\section{SERVIS TASARIMI}

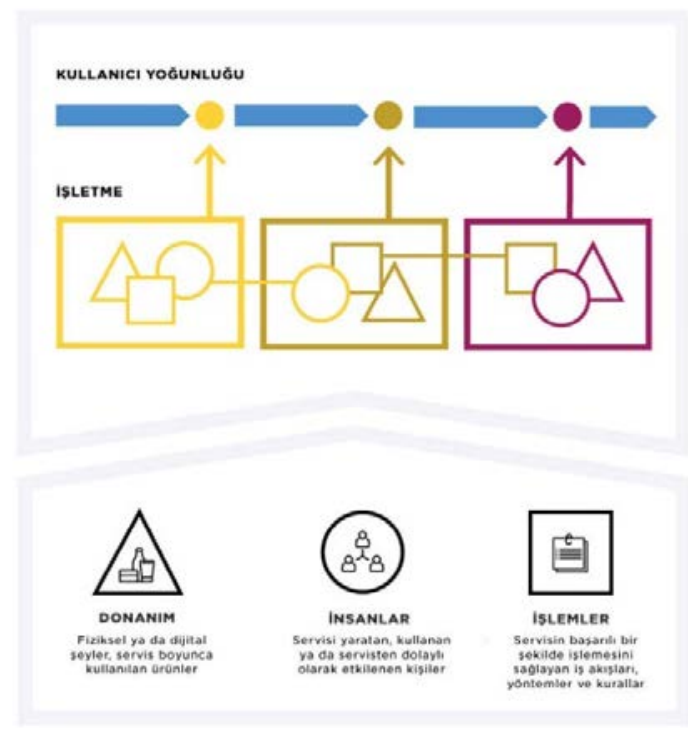

Şekil 2. Servis Tasarımı İşleyişi (URL-4)

Batur'un teknolojinin mimari içindeki yerine dair görüşleri Özkan'ın (2007, s.128) araştırmasında; "Günümüzün teknolojisi o kadar baskın durumda ki teknolojiyi yadsımak artık olanaklı değil, mimariyi onsuz düşünmek mümkün değil. Bugünün teknolojisinin varlığını kabul ederek ama geçmişte yaşanan deneyimleri de yadsımadan mimariyi yorumlamak şeklinde bir eğilim var" cümleleri ile aktarılmaktadır. Özkan'a (2007, s.130) göre; 21. yüzyıl; teknoloji ve iletişim çağının sürekli gelişimi ile birlikte tüketim olgusunun daha da arttığı bir dönemdir. Üretimin hızlanmasıyla tüketim de paralel olarak hızlanmaktadır. Bu nedenle tasarım, geçmiş dönemlerde görülen estetik 
ya da fonksiyonellik karmaşasından uzak; kullanıcıyı temel alan bir yaklaşımla gerçekleşmektedir. Teknolojideki gelişmelerin tasarım eylemini şekillendirmiş olduğu bu noktada, servis tasarımı, temas noktalarının kullanıcı odaklı tasarlanmasıdır (URL-2). Dolayısıyla alan sınırlanması yoktur. Birçok farklı alan ve eyleme uygulanabilmektedir. Tasarımcılar insanların birbirleriyle ve sistemle nasıl etkileşim kurduğunu ve süreçte kullanılan araçları göz önüne almaktadırlar.

Günümüz mekân tasarımında süreç disiplinler arası ilerlemektedir. Süreci gerçekleştiren ekibi, iç mimarlar, mimarlar, servis tasarımcıları, iletişimciler ve tasarım araştırmacıları oluşturmaktadır. Bir mekânın, uzman kiş̧iler tarafından bütüncül bir yaklaşım ile doğrudan çalışanın ve dolaylı olarak da kullanıcının deneyimini geliştirmek amacıyla planlanması ve düzenlenmesi belirtilen ekibin uyumlu bir şekilde çalışmasını gerektirmektedir. Mekân tasarımı kapsamında temas noktalarının, kullanıcılar tarafından sorunsuzca ve çalışması gerektiği gibi kullanılabilmesi için, servisin tasarım odaklı sürecinin kullanıcıları merkeze alan bir yöntem ile kolektif bir ekip tarafından yürütülmesi gerekmektedir (URL-2). Servis tasarımı metodolojilerinin amacı, kullanıcıların ihtiyaçlarına göre tasarım yapmaktır. Bu bağlamda en önemli nokta, kullanıcıların davranışları bağlamında intiyaçlarını ve isteklerini belirli atölyeler ile tespit ederek, elde edilen bulgular ışığında servis planı oluşturmak ve en sağlıklı sonuca ulaşmaktır.

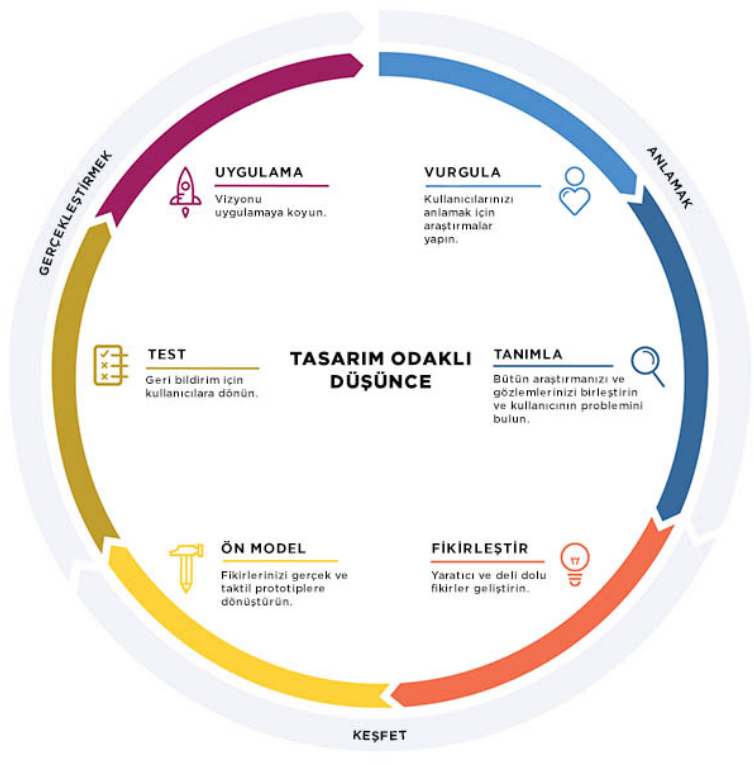

Şekil 3. Tasarım Odaklı Düşünme (URL-4).

G. Lynn Shostack tarafından 1982'de ilk kez kullanılan Servis Tasarımı kavramının en önemli noktalarından biri, mekânın kullanıcıyla olan etkileşimlerini detaylandıran servis planıdır (URL-2). Servis planı, tasarım odaklı düşünme yaklaşımı temel alınarak oluşturulmaktadır. Tasarım odaklı düşünme, kullanıcıyı merkeze alarak yapılan araştırmalar ve analizler dâhilinde belirlenen problemlere yeni bir bakış açısı ile yaklaşma, yenilikçi ve yaratıcı çözümler geliştirme süreci olarak tanımlanabilmektedir. Tasarım odaklı düşünme süreci, tasarımı kullanması öngörülen insanların psikolojik ve fiziksel intiyaçlarının araştıııması ile başlamaktadır. Devamında, ulaşılan bulgular ışığında problemlerin tanımlanmasını ve farklı uzmanlık alanlarına sahip ekip üyelerinin bir araya gelerek yenilikçi ve yaratıcı çözümler üretmesini kapsamaktadır. Tanımlanan bu aşamalar sonrasında, üretilen çözümler dâhilinde tasarım somut hale getirilmekte ve kullanıcılardan alınan geri bildirimler ile geliştirilmektedir (Şekil 3). Bu yöntem ile tasarımın üretim amacına ve kullanıcısına uygunluğu arttırımaktadır (URL-3) 
Servis planının oluşumu, insan odaklı düşünerek kullanıcı deneyimini odak noktasına almak ile başlamaktadır. Organize yaratıcılık deneyimi ve sürecin tasarlanması devam eden adımlardır. Kullanıcının mekân ile etkileşime geçtiği temas noktalarının tasarlanması ile düzen tasarımı sağlanmış olur. Son olarak kâğıt üzerinde analizler ile oluşturulan bu süreç görselleştirme çalışmaları ile nesneleştirilir (URL-2). Tanımlanmış adımların sonucunda tamamlanan plan ile birlikte tasarlanan mekâna kullanıcı değeri katılması sağlanmaktadır. Servis planı, öncesinde bahsettiğimiz farklı alanda uzmanlaşmış birçok tasarımcının birlikte çalışması ile gerçekleşir. Bu tasarımcılar, farklı ölçeklerde nitelikli tasarımlar geliştirme ve bu ölçekler arasındaki ilişkileri bütüncül olarak kurgulamada uzmanlaşarak, tasarım sürecini bütüncül tasarım anlayışı ile pekiştirmektedirler.

Servis tasarımı bağlamında önem kazanan diğer kavramlar inovasyon olarak isimlendirilen yenileşim, tasarım olarak isimlendirilen estetik ve marka olarak isimlendirilen kullanıcı kavramlarıdır. Kullanıcı tarafından tecrübe edilen her deneyimin geliştirilmesi mümkündür. Bu bilgiye paralel bir kapsamda, servis tasarımı kullanıcı deneyiminin her noktada olabildiğince yüksek olması amacını benimsemektedir. Kullanıcı ve mekânın etkileşime girdiği temas noktaları olumlu ve olumsuz olarak sınıflandırılmaktadır. Tasarımcılar bu süreçte, olumsuz olan deneyimlerin, olumluya dönmesi için bahsedilen servis planını oluşturmaktadır. Belirlenen etkileşimin sağlanacağı temas noktaları, markanın kimliğini ve mekânın fonksiyonunu yansıtacak şekilde tasarlanır. Bu noktada servis tasarımı, mekânın kullanıcısına en olumlu deneyimi yaşatması ve etkileşimi en yüksek seviye de sağlaması amacıyla izlenen yol olarak tanımlanabilmektedir.

Servis tasarımı kapsamında, günümüz tasarlama eylemi süreci değerlendirdiğinde uzman tasarımcıların, olumsuz deneyim sağlayan temas noktalarını belirleyerek çözüme ulaştırmış olması gerekmektedir. En önemli nokta, kullanıcının her zaman odak noktasında olması gerekliliğidir. Ayrıca, servis tasarımı kavramı bağlamında, bir hizmeti sağlamak için teknoloji her zaman ön planda olmaktadır. Teknoloji içeren temas noktalarının, değişen kullanıcı gereksinimleri karşısında hızlı değişime izin verecek kadar esnek ve fonksiyonel olması gerekmektedir. Fonksiyonlar ve kullanıcı ihtiyaçları en iyi şekilde eşleşme sağlamalıdır. Bu noktada, servis tasarımı anlayışını benimseyerek ürün ortaya koyan ofis yapılanmalarının örnekleri incelenerek, iç mimarın bu kapsamdaki rolü irdelenecektir.

\section{4. İC MEKÂN TASARIMININ SERVIS TASARIMI KAPSAMINDA TANIMLANMASI: DENEYIM TASARIMI OFISLERI}

Günümüzde tasarım ofisleri üretim şirketlerinden inovasyon şirketlerine doğru dönüşmektedir. Bu süreçte müşterilerin gelecekteki istek ve ihtiyaçları analiz edilmekte, onların beklentilerinden yola çıkılarak tasarım gerçekleşmektedir. Bu tasarım yaklaşımı kapsamında, insanı tasarımlarının odak noktasına yerleştirmeyi amaçlayan yeni ofis yapılanmaları gelişmektedir. Bu yapılanmalar deneyim ofisleri başlığı altında iç mimarlar, mimarlar, servis tasarımcıları, iletişimciler ve tasarım araştırmacılarından oluşmaktadır.

Kullanıcı deneyimini tasarlayan ofis yapılanmalarını incelediğimizde, normal tasarım ofislerinden farkları 360 derece tasarım başlığı altında bütüncül bir tasarım anlayışı sunmaları olarak nitelendirilebilmektedir. Temel amaçları, mekânı deneyimleyen kullanıcılarının mekân ile etkileşime geçecekleri temas noktalarını düşünerek o 
noktalarda tasarım gerçekleştirmektir. Marka, mimari ve dijital olmak üzere üç noktada tasarımlarını ilerletmek bu anlayışın odağında yer almaktadır.

Marka en yalın haliyle, insanların sahip olduğu izlenimdir. İç mekân tasarımı bu izlenimin oluşturulmasında son derece kritik bir yer tutmaktadır. Bu süreçte birçok farklı uzmandan oluşan ekip, atölyeler aracılığıyla kullanıcıların mekânla etkileşime geçtiği noktaları belirlerken her bir uzmanın farklı bakış açısı ile sürece katkısını sağlaması önemli bir rol oynamaktadır. Tüm bu sürecin amacı işlevlerini olabildiğince iyi bir şekilde yerine getiren, müşterilerin kalplerinde ve zihinlerinde kalıcı duygusal tepkiler, bağlar ve izlenimler uyandıran mekânlar kurgulamaktır (URL-5).

Mekân kullanımları arasındaki sınırların giderek kalktığı gözlemlenebilmektedir. Günlük yaşam içinde gerçekleştirilen birçok eylem mekânları şekillendirmektedir. Örneğin, çalışma mekânları günümüz kullanıcısının intiyaçları dâhilinde yeniden şekillenerek; kullanıcısına daha iyi bir yaşam standardı sunabilmek amacıyla içerisinde farklı çalışma tarzlarına olanak sağlayan alternatif mekanları barındırmanın yanı sıra rekreasyon alanlarını da barındırmaktadır. Günümüzde iç mekân tasarımı sadece fonksiyon ve estetik ile ilgili değildir. Kapsamlı bir iç mekân tasarımı, çalışanların ve kullanıcılarının geri bildirimleri etrafında şekillenmektedir. Bu sürecin en önemli kısmı, kullanıcıların mekânla temas ettiği noktalardır. Belirtilen bu amaca ulaşmak için servis tasarımı metodolojileri önemli bir yer tutmaktadır.

$\mathrm{Bu}$ bilgiler ışığında, servis tasarımının kapsamını oluşturan kullanıcı araştırması, kullanıcı yolculuğu analizi, deneyim haritalandırımasını içeren servis planı yapılırken iç mimari ve mimari ekip, marka ekibi, endüstriyel tasarımcı ekip birlikte çalışmaktadır. Bu kolektif yapılanma içinde farklı alanlarda uzmanlaşmış tasarımcılar birbirlerini besleyerek, süreci en hızlı ve verimli şekilde sonuçlandırmaktadırlar.

Dünyada ve Türkiye'de az sayıda örnek bulunmakla beraber; örneklerinin sayılarının gün geçtikçe arttığı da gözlemlenmektedir. Bu örnekler içinde Türkiye'de "Cloud 7 Hotel" iç mimari tasarım odağında servis tasarımını da barındıran önemli bir kolektif tasarımı örneğidir. Bir şehir oteli olan mekânın marka, mimari ve dijital tasarımları bütüncül tasarım anlayışı ile gerçekleştirilmiştir. Otel bilinen bir otel iç mekânı düzeninde tasarlanmamıştır. Resepsiyon, lobi alanı gibi tanımlı mekânlar yerine kullanıcıların ve işletmecilerin farklı ruhsal ve fiziksel gereksinimlerine uygun, uyum sağlayan alanlar tasarlanmıştır (Fot. 1). Kullanıcıların kendi deneyimlerini oluşturmaları adına teknolojik bir alt yapı ile kurgulanmıştır (URL-6).

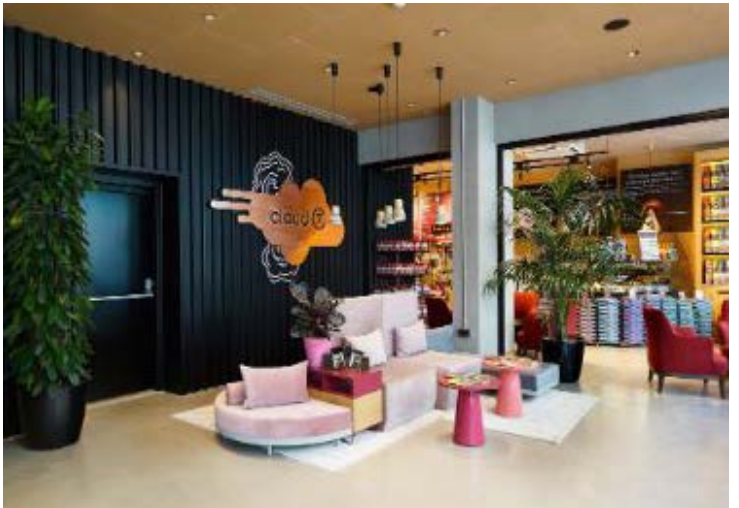

Fot. 1a. Cloud 7 Hotel (URL-6).

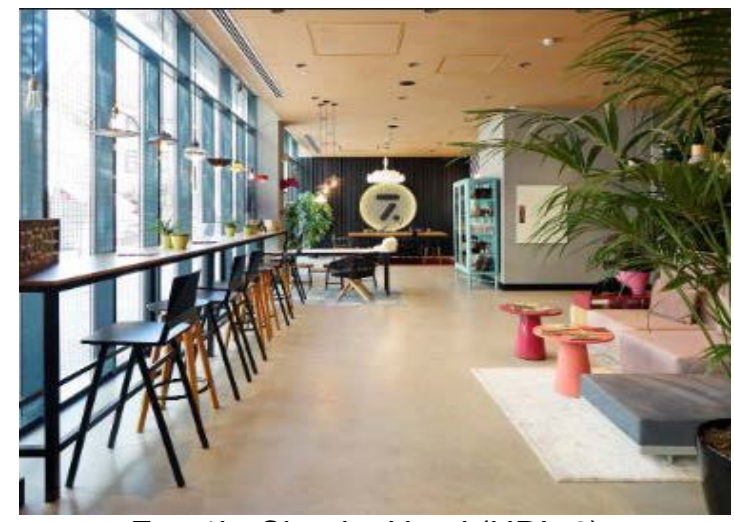

Fot. 1b. Cloud 7 Hotel (URL-6). 
Avrupa'nın banka zincirlerinden biri olan "UniCredit Bulbank", kolektif bir iç mekân tasarımı kapsamında yenilikçi çözümlerle tasarlanmış bir örnek olarak karşımıza çıkmaktadır. Çalışanların ve kullanıcıların pozitif deneyim yaşamasını odak noktasına alan deneyim ofisi, ileri teknoloji ürünler ve modern mobilyaların kullanımıyla mekânı özelleştirmiştir. Servis Tasarımı metodolojileri ile kullanıcı profili belirlenen ve kullanıcı yolculuğu tasarlanan proje Sofya'da uygulanmıştır. Projenin hayata geçirilmesinin ardından yapılan araştırmalarda, kullanıcı sirkülasyonunun ve satışların arttığı tespit edilmiştir. Banka kullanıcısı için en sıkıcı olarak nitelenen bekleme eylemini, kullanıcıyı özel hissettirerek aşmak hedeflenmiştir. Bu amaç bağlamında, alışıldık banka tasarımlarının aksine özelleştirilmiş bölümler oluşturulmuş ve iç mekân biçimlendirilmiştir. Kullanıcılardan alınan geri bildirimler kapsamında, kullanıcı memnuniyetinin artış gösterdiği belirlenmiştir (URL-7) (Fot. 2.)

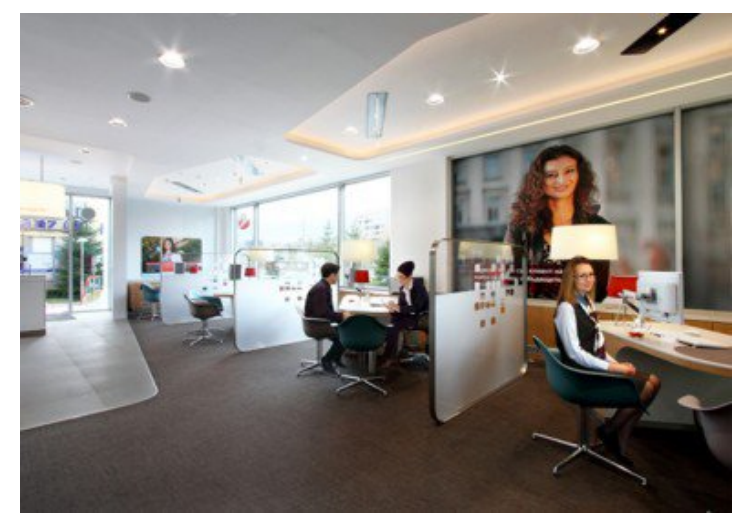

Fot. 2a. Uncredit Bulbank (URL-7).

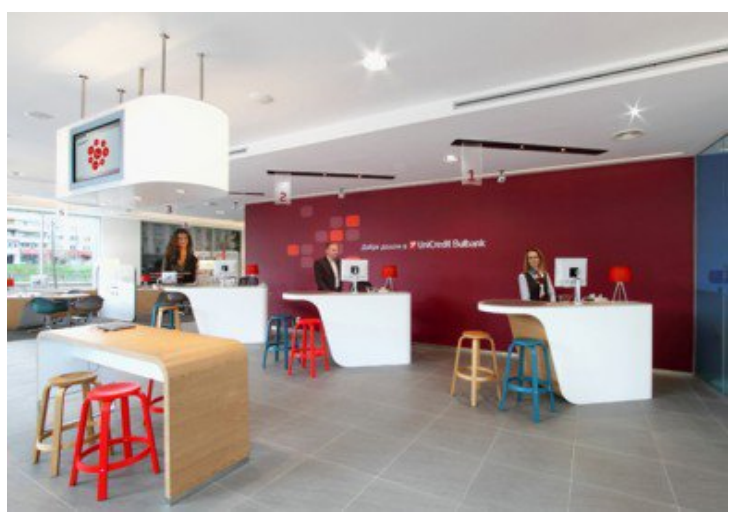

Fot. 2b. Uncredit Bulbank (URL-7).

Dünyadan bir diğer örnek ise kullanıcısının istek ve intiyaçlarına göre kurgulanan "Raiffeisen Bank" isimli projedir. Kolektif bir ekibin oluşturduğu deneyim tasarımı ofisinin servis tasarımı ekibi 4 şehirde 20 müşteriyle gerçekleştirdiği görüşmeler sonrasında, bankanın yeni tasarım stratejisini oluşturmuştur. Yapılan atölye çalışmaları ile birlikte kullanıcıya en iyi hizmeti sunabilmek hedeflenmiştir. Bu uygulama, müşteri deneyimini iyileştirmenin yanı sıra kurumun maliyetlerini de düşürmüştür (URL-8). İç mekân tasarımı bu bilgiler ışığında belirlenen kullanıcı yolculuğu kurgusunun paralelinde, özel modüllerin kullanımı ile sağlanmış olan esnek tasarım anlayışı ile biçimlendirilerek deneyimi kişiye özel oluşturmayı amaçlamıştır (Fot. 3).

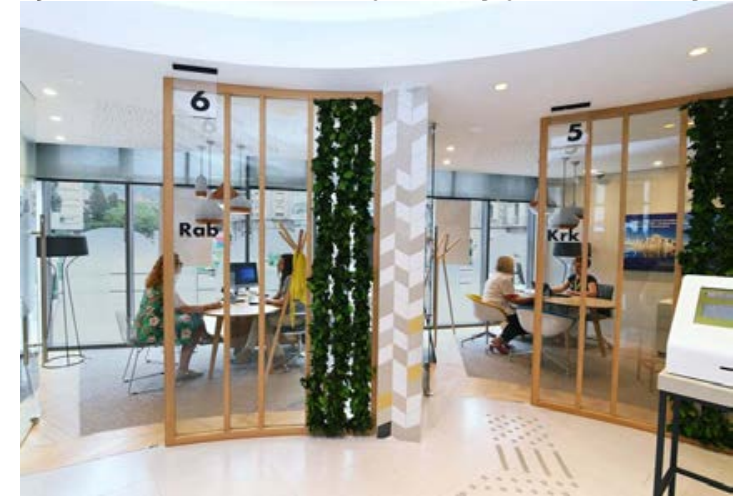

Fot. 3a. Raiffeisen Bank (URL-8).

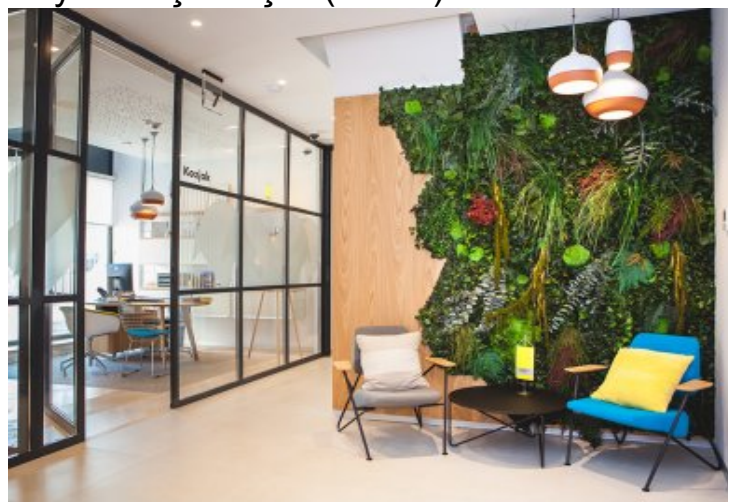

Fot. 3b. Raiffeisen Bank (URL-8). 


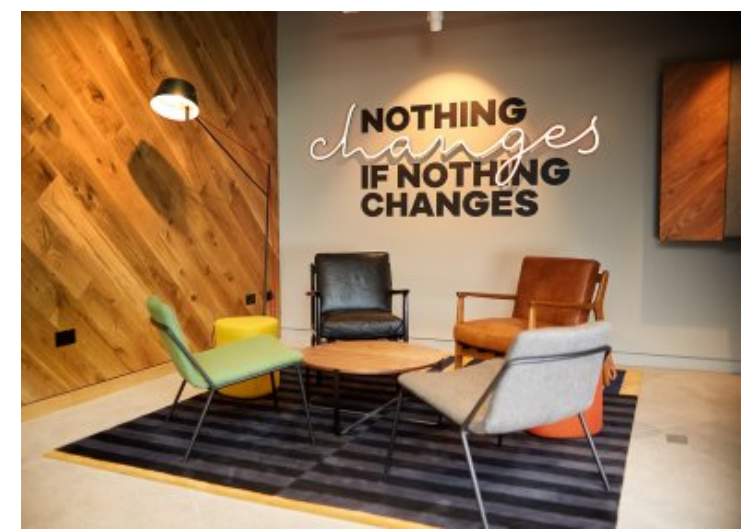

Fot. 4a. B Works Bank (URL-9).

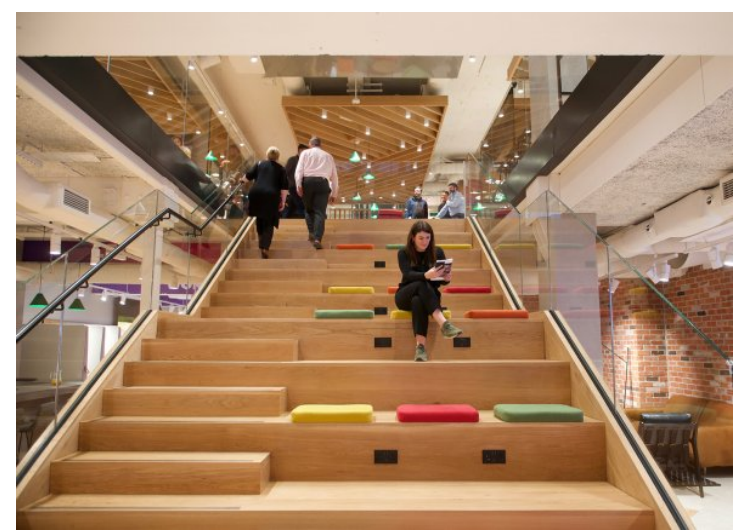

Fot. 4b. B Works Bank (URL-9).

Bir diğer örnekte ise yeni nesil banka anlayışı ile tasarlanmış "B Works" bankaların kullanıcısı ile olan ilişkilerine tamamen farklı bir açıdan yaklaşmaktadır. Yapılan servis planı temelinde, müşterilerin ve çalışanların intiyaçlarını dengeleyen iç mekân kurgusu geliştirilmiştir (Fot. 4). Temelde banka deneyimiyle pek ilişkili olmayabilecek, fakat müşteriyle etkileşimi arttıran yenilikçi bir yer olarak tasarlanmıştır. Kullanıcıya ve çalışana sosyalleşme imkânı sağlayan esnek ve fonksiyonel bir mekân oluşturulması hedeflenmiştir. Bu hedef dâhilinde oluşturulan mekânın, yeni fikirlerin üretilebildiği, paylaşılabildiği ve ortak çalışmayı kolaylaştıran bir yer olması öngörülmüştür. "Öğren. Çalış. Bankanı Kullan." sloganı ile yeni nesil kullanıcı odağında şekillenen iç mekân renkli ve dinamik bir anlayış ile kurgulanmıştır (URL-9).

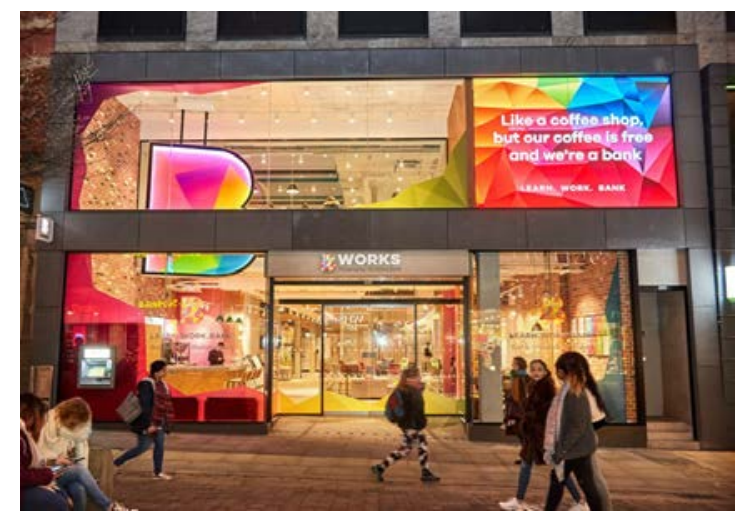

Fot. 4c. B Works Bank (URL-9).

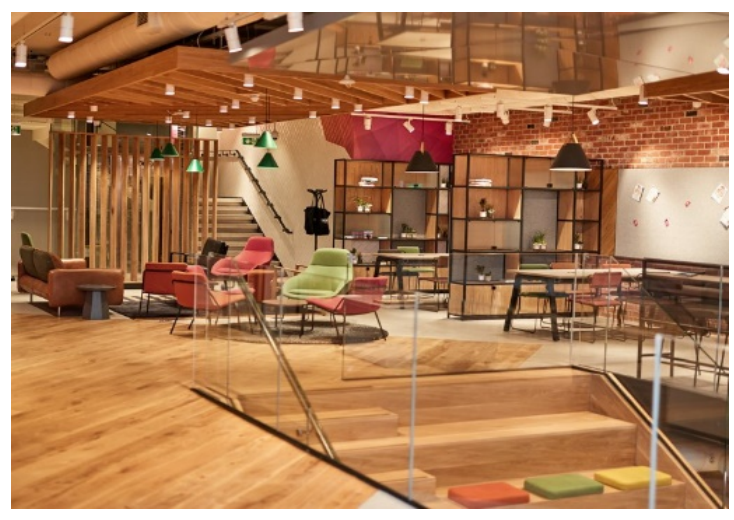

Fot. 4d. B Works Bank (URL-9).

\section{DEĞERLENDİRME VE SONUÇ}

Yukarıda görüldüğü üzere bu çalışmada, tasarım, tasarımcı ve iç mimar kavramlarının tanımlanmasının ardından servis tasarımı yaklaşımı incelenmiştir. Devamında İç mimarın gelecekteki rolüne dair birçok farklı uzmanlık alanının tek bir çatı altında çalıştığı ofis yapılanmalarının irdelendiği bu çalışmada, tasarım sürecinin "insan odaklı" ilerlemesi ve sadece mekân tasarımının değil kullanıcının mekân ile etkileşime geçebileceği temas noktalarının da tasarlanması olarak değerlendirilmesi ve bu sürece dair bir farkındalık oluşturulması hedeflenmiştir. Örnekler üzerinden yapılan irdelemeler sonucunda deneyim tasarımı ofisleri üzerinden İç Mimarlık mesleğinin gelecekteki kapsamıyla ilgili aşağıdaki çıkarımlara ulaşılmıştır; 
- Bu çalışma ile servis tasarımının irdelenen tasarım sürecinin, farklı uzmanlık alanlarına sahip tasarımcılar bağlamında işlenmesi değerlendirilerek, tasarımcının/iç mimarın süreç yaklaşım farkındalığının arttırıldığı düşünülmektedir. İç Mimarın, servis tasarımını ve kullanıcı deneyimini benimseyen ofis çatısı altında daha verimli işler ortaya koyabileceği ve bu durumun tasarımcıya süreç kontrolü sağladığı düşünülmektedir.

- Hızlı gelişen teknoloji ile birlikte bulunduğumuz yüzyılın tasarım anlayışı her türlü gereksinimlere, dönüşümlere, gelişmelere açık alternatif çözümlere yönelmektedir. Kolektif bir ekip tarafından gerçekleştirilen süreç, çağdaş, bilimsel ve teknik yöntemler ile kapsamlı tasarımları kısa sürede uygulamaya olanak sağlamaktadır.

- Belirtilen kolektif çalışmanın faydalı yönlerinin biri her uzmanlık alanının birbirini beslemesi olarak tanımlanabilmektedir. Bu durumun projenin tasarlanma ve uygulanma sürecini kısaltmak olduğu öngörülmektedir. Disiplinler arası etkileşim ile interaktif tasarım sağlanmaktadır. İç mimari, mimari alanlarında yetkin tasarımcıları, pazarlama, ekonomi, grafik tasarım, endüstriyel tasarım ve araştırma temelli interaktif tasarım alanlarında yetkin tüm ekip üyelerini beslemektedir.

- Günümüzde teknolojinin geldiği nokta bağlamında yorumladığımızda; Servis tasarımı kavramı kapsamında farklı disiplinlerden insanlarla işbirliği yapmak, artık birçok işlevi bir arada barındırmakta olan iç mekân tasarım sürecinin kullanıcının fiziksel ve psikolojik algısı bağlamında etkili olması için önemli bir yol olduğu öngörülmektedir.

- Sonuç olarak günümüz ve yakın gelecekteki tanımı ile İç mimar, teknolojinin getirdiği avantajları en kapsamlı yoluyla kullanabilen ve bu süreçte mekân örgütlenmesi amacının yanı sıra mekân ve kullanıcının temas noktalarını da düşünerek çalışabilen tasarımcı kimliğine sahiptir. 


\section{KAYNAKLAR}

Atakan, Gökçe, Yaratıcı Tasarım Sürecinde Bilişsel Yaklaşım Ve Üstbilişsel Farkındalık, Hacettepe Üniversitesi, Sosyal Bilimler Enstitüsü, Yüksek Lisans Tezi, Ankara 2014.

Demirarslan, Deniz, "Sedad Hakkı Eldem Eserlerinde Bütüncül Tasarım Kapsamında İç Mekânın Tasarımı Ve Etkileri”, Kesit Akademi Dergisi, Eylül 2018, s. 32-56.

Demirarslan, Deniz, Demirarslan, Kazım Onur, "Çevre Koruma Bilinci Bağlamında İç Mekânın Tasarımında Disiplinler Arası Bir Yaklaşım: İç Mimarlık ve Çevre Mühendisliği İlişkisi", Doğal Afetler ve Çevre Dergisi, Temmuz 2017, s. 112-128.

Hayles, Carolyn S., "Environmentally Sustainable Interior Design: A Snapshot of Current Supply of and Demand for Green, Sustainable or Fair Trade Products for Interior Design", International Journal of Sustainable Built Environment, Haziran 2015, 4, s. 100-108.

Kaptan, Burak, İçmimarlığın Oluşum ve Örgütlenme Süreci, Anadolu Üniversitesi Sanat Dergisi, Eskişehir 1998.

Kazamia, Kika L., Kafaridou, Marianna O., "How a Designer Can Support Sustainability in a Creative Way", International Design Conference - Design 2010, Dubrovnik, Crotia, s. $573-580$.

Ökten, Gürünay, İc Mimarlık Mesleği Özelinde Tasarım Ve Tasarımcı Kavramlarının Algılanışı Ve 'Tasarımcı Kimdir?' Sorusuna Yanıt Aramak Üzerine Bir Okuma Türkiye Örneği, Hacettepe Üniversitesi, Sosyal Bilimler Enstitüsü, Yüksek Lisans Tezi, Ankara 2012.

Özkan, Ayşen, lç Mekân Tasarımı Kuram Ve Yöntemleri Işığında Günümüz Türk Iç Mekân Tasarımcıları Ve Tasarım Anlayışlarına Bir Yaklaşım, Hacettepe Üniversitesi, Sosyal Bilimler Enstitüsü, Yüksek Lisans Tezi, Ankara 2007.

Türk Dil Kurumu, 2019. (Son Erişim Tarihi: 10.02.2019, 15.00)

Vidalis, Michael A., Total Work of Art, Architectural Review, http://www.greekarchitects.gr/en/architectural-review/gesamtkunstwerk-id3185 (Son Erişim Tarihi: 20.11.2019, 20.15)

URL-1: Budak, Mustafa Ajlan, Holistik Düşünce Nedir?, 2011. https://akillitasarim.wordpress.com/2011/01/16/holistik-dusunce-nedir/ adresinden alındı. (Son Erişim Tarihi: 10.02.2019)

URL-2: Gibbons, Sarah, Service Design 101. Nielsen Norman Group, 2017. https://www.nngroup.com/articles/service-design-101/ adresinden alındı. (Son Erişim Tarihi: 10.02.2019, 15.00)

URL-3: Gibbons, Sarah, Design Thinking 101. Nielsen Norman Group, 2016 https://www.nngroup.com/articles/design-thinking/ adresinden alındı. (Son Erişim Tarihi: $10.02 .2019,15.00)$ 
URL-4: Cindoğlu, Beylem, Servis Tasarımı 101: Daha lyi Servisler Kurgularken Bilmeniz Gerekenler. Sherpa, 2018. https://sherpa.blog/makale/service-design-servistasarimi-nedir/adresinden alındı. (Son Erişim Tarihi: 10.02.2019, 15.00)

URL-5: Biçer, Selin, Marka, Mimari, Dijital. Arkitera, 2012.

http://www.arkitera.com/soylesi/303/marka-mimari-dijital adresinden alındı. (Son Erişim Tarihi: 10.02.2019, 15.00)

URL-6: http://i-amistanbul.com.tr/cloud7 adresinden alındı. (Son Erişim Tarihi: 25.04.2019, 23.10)

URL-7: https://i-amonline.com/case-study/unicredit-bulbank-branch-experience-design/ adresinden alındı. (Son Erişim Tarihi: 25.04.2019, 23.10)

URL-8: http://www.i-amistanbul.com.tr/raiffeisen-bank adresinden alındı. (Son Erişim Tarihi: 25.04.2019, 23.10)

URL-9: http://www.i-amistanbul.com.tr/b-works-manchester adresinden alındı. (Son Erişim Tarihi: 25.04.2019, 23.10) 